\title{
LIBERDADE NA NECESSIDADE OU A RESOLUÇÃO DO DUALISMO SEGUNDO JONAS*
}

\author{
Lilian S. G. Fonseca \\ Universidade Federal de Minas Gerais
}

\begin{abstract}
This article aims to approach the dualism, a very recurrent theme in the Jonas' works, especially in the period preceding his ethical reflection. Problem whose face, Jonas considers absolutely necessary to enable his ethical discussion itself. And that persists throughout all long his reflection, as shown the text - chosen to guide this discussion -, entitled "Evolution and Freedom", published four years after The Imperative of Responsibility. Rather than presenting a less discussed aspect of the Jonas' entire thought, it means to illuminate the connection between this basic issue and his ethical formulation that placed him in the philosophical world scene.
\end{abstract}

Keywords: Jonas, dualism, freedom, necessity, Ethics.

Resumo: $O$ artigo tem o objetivo de abordar o dualismo, um tema bastante recorrente na obra jonasiana, desde o período que antecede a sua reflexão ética. Problema cujo enfrentamento, Jonas considera indispensável para possibilitar sua discussão ética propriamente dita. E que persiste ao longo de toda sua reflexão, como se pode ver no texto escolhido para conduzir a exposição, intitulado "Evolução e liberdade", publicado quatro anos depois de 0 Princípio Responsabilidade. Mais que apresentar um aspecto menos abordado do conjunto do pensamento do autor; trata-se de iluminar a conexão entre essa questão basilar e a formulação ética que o projetou na cena filosófica mundial.

Palavras-chave: Jonas, dualismo, liberdade, necessidade, ética.

\footnotetext{
* A versão original desse texto foi escrita em 2006, durante o estágio na Université Catholique de Louvain - Louvain-la-Neuve - Bélgica, dentro do PDEE, financiado pela CAPES. 


\section{Introdução}

Antes de iniciar a minha exposição, gostaria de parabenizar e agradecer ao Prof. Robinson dos Santos e a todos que colaboraram para a realização do $1^{\underline{a}}$ Colóquio Hans Jonas, pela oportunidade que esse evento oferece de congregar estudiosos, pesquisadores e interessados pela obra de um filósofo tão importante para o nosso conturbado momento histórico, mas, ainda hoje, insuficientemente conhecido, estudado e discutido no meio acadêmico brasileiro.

De fato, habitualmente, Jonas é mencionado, quase sempre, em função de sua obra de maturidade, aquela que o projetou no cenário filosófico norte-americano e europeu no final da década de 70, O Princípio Responsabilidade $[P R]$ (1979), um trabalho de peso e relevância incontestáveis, merecedor, portanto, de todo o reconhecimento a ele dedicado. Além do $P R$, no máximo, menciona-se também uma obra posterior Técnica, Medicina e Ética ${ }^{1}$ [TME] (1985), que constitui uma aplicação de seu "princípio responsabilidade" à reflexão do problema das biotecnologias dirigidas ao ser humano, notadamente no campo das pesquisas e da medicina.

Todavia, Hans Jonas não é somente o "filósofo da responsabili-dade"2. Sua obra abrange outras áreas de investigação que, na verdade, culminam com o $P R$ e o $T M E$, na reflexão ética, mas sua trajetória intelectual começa muito antes, na década de 30 e sua produção - bastante extensa - contém outras obras basilares e, pode-se dizer; indispensáveis à justa compreensão de sua formulação ética.

Para iluminar um lado menos abordado do pensamento de Jonas, pretende-se aqui, - extrapolando o objetivo primordial deste Colóquio que é promover o debate em torno de sua obra principal, justamente, $O$ princípio responsabilidade - focalizar um tema bastante recorrente em sua obra, especialmente na fase anterior à elaboração ética. Questão, de fato complexa que o desafia desde as primeiras reflexões e pode ser designada como o

1. Obra que, no Brasil, é bem mais conhecida por profissionais da área biomédica, com a qual Jonas nela dialoga, do que ainda, infelizmente, por estudiosos da área filosófica.

2. Aliás, segundo Olivier Depré, Hans Jonas é conhecido como o "pensador da liberdade". (DEPRÉ, O. Hans Jonas. 1903 - 1993. Paris: Ellipses, 2003, p. 23). 
problema do dualismo, visto por ele como uma questão a ser, forçosamente, enfrentada para abrir caminho à sua concepção ética posterior.

Sem almejar esgotar o tema, apenas lançar luz a essa parte da obra jonasiana, injustamente menos discutida, a presente exposição divide-se em 3 momentos: 1. O dualismo como problema central na reflexão filosófica jonasiana; 2. A solução do dualismo segundo Hans Jonas; 3. Conseqüências dessa resolução e suma Conclusão.

\section{0 dualismo como problema central na reflexão filosófica jonasiana}

Nosso ponto de partida será a constatação de que o problema do dualismo constitui, por assim dizer, o leitmotiv de toda a reflexão filosófica jonasiana. $\mathrm{O}$ que nos leva necessariamente a perguntar: por que Jonas atribui ao dualismo uma importância tão grande e por que essa questão precisa ser tão imperiosamente solucionada?

Como assinalado por Nathalie Frogneux, o próprio Jonas resume sua trajetória como uma "démarche filosófica inteiramente consagrada à resolução do dualismo, para pensar a dignidade do homem agindo no interior do mundo onde ele se encontra” (DH, p. 16/VM, XIII n. 2. Itálico nosso $)^{3}$. Esse aspecto é, portanto, crucial ao esclarecer porque, desde as suas primeiras obras sobre a gnose, o tema do dualismo já se mostra como eixo central de sua exposição.

Frogneux ressalta o pioneirismo de Jonas ao descrever o dualismo gnóstico em toda sua originalidade e radicalidade, sem reduzi-lo ou atribuir sua origem a formas anteriores seja o dualismo persa (mazdeano ou zoroastriano), que é pro-cósmico, enquanto o dualismo anti-cósmico gnóstico vê o mundo como o lugar por excelência do $\mathrm{mal}^{4}$; seja o dualismo grego (órfico-pitagórico-platônico) no qual, embora desvalorizado como imperfeito (sobretudo conforme a versão platônica), o cosmos permanece como uma imagem da perfeição na qual o Demiurgo se inspirou para criá-lo, enquanto o pensamento gnóstico é totalmente hostil ao mundo como um todo. A autora adverte ainda que não há uma oposição entre dualismo e monismo,

\footnotetext{
3. A mesma citação aparece nos dois textos de Frogneux, aqui focalizados.

4. O cosmos gnóstico "não tem nada do caráter venerável do cosmos grego" (PhV, p. 224).
} 
como há, por exemplo, entre diteísmo e monoteísmo; nossa exposição tentará mostrar por que.

Aos olhos de Jonas, por sua hostilidade em relação ao mundo, o dualismo gnóstico constitui, "uma ruptura absoluta, uma torção ou uma perversão da cadeia do ser que atinge as raízes mesmas da vida humana no mundo" (VM, p. 27). Essa ruptura se traduz, na dimensão humana, como um sentimento de isolamento do homem em sua condição de ser solitário, num mundo natural hostil e mau; sentimento que se encontra alojado na raiz do pensamento gnóstico. Resta ao homem, como um ser "exilado no mundo", buscar abrigo no "ser divino" 5 .

Segundo Jonas, a conseqüência mais nefasta desse dualismo homem/mundo é, portanto, o niilismo ${ }^{6}$ que, como bem apontado por Frogneux, manifesta-se numa "metafísica do ser-no-mundo que, em sua raiz, torna a ação vã, tanto para o homem que a realiza quanto para o mundo que a sofre” (VM, p. 31). Sendo assim, na base de sua crítica ao dualismo gnóstico encontram-se, por um lado, as críticas ao niilismo e, por outro, ao ceticismo moral, como a sua pior conseqüência. Nesse sentido, a crítica jonasiana dirige-se, não ao dualismo como tal, mas, a seus efeitos - cético e niilista - que atingem a antropologia, sobretudo, no que tange à esfera da ação. Por esse motivo, Frogneux observa que a tarefa filosófica assumida, destarte, por Jonas, visa recuperar um ponto comum entre o homem e o mundo sem, no entanto, jamais pretender reduzir um ao outro.

Além desse dualismo homem/mundo (ou cósmico-antropológico), Jonas enfrenta ainda outro dualismo. Trata-se do dualismo espírito/matéria (ou psico-físico) $^{7}$ retomado com todo vigor no período moderno, desde René Descartes com a separação radical entre res cogitans e res extensa estabelecendo que a natureza se restringe exclusivamente à segunda, tornando possível uma abordagem do mundo natural meramente quantitativa e

\footnotetext{
5. Cabe mencionar a concepção gnóstica da existência de dois deuses ou princípios divinos antagônicos: um deus supra-mundano bom e um demiurgo mau, origem desse mundo também mau. (VM, pp. 29 e Ss.)

6. "Essa cisão entre o homem e a realidade total está na base do nillismo" (PhV, p. 237) - o qual é apontado por Jonas como traço comum ao pensamento gnóstico antigo e ao existencialismo moderno (ver Ensaio IX de PhV - "Gnose, existencialisme et nihilisme" - p. 217-238).

7. Na antigüidade, os pólos corpo/alma (soma/psyqué) eram realidades distintas que, todavia, formavam uma unidade.
} 
mecanicista, adotando como modelo a aplicação do método matemático na nova ciência da física.

Frogneux afirma que, para Jonas: "o separatismo cartesiano seria motivado pela vontade de fundar a metodologia e a metafísica das ciências naturais" ( $V M$, p. 121). Logo, segundo a autora, na perspectiva jonasiana, Descartes é, mais do que o precursor da filosofia da consciência ou da subjetividade, o fundador das ciências modernas. Além disso, o que Jonas confronta nessa metafísica moderna é, precisamente, um novo tipo de dualismo no qual os pólos opostos manifestam-se como "realidades autosuficientes" (Idem), ou seja, dimensões autônomas, enquanto que no dualismo clássico os pólos se encontravam como oposições correlatas ou interdependentes.

Jonas identifica "um novo tipo de polaridade (...) manifesta por pares tais como sujeito/objeto, espírito/natureza, consciência/espacialidade, interioridade/exterioridade, onde o segundo termo goza de uma realidade independente e, finalmente, mesmo anterior" (PhL, p. 72/VM, p. 121) . $^{8}$ Frogneux ressalta que, em termos cartesianos, os primeiros termos referem-se à res cogitans e os segundos à res extensa e que a autonomia entre eles decorre da recíproca exclusão de seus respectivos domínios. Jonas, porém, critica tal cisão, como rígida separação, entre outras razões, por resultar na total recusa da subjetividade no âmbito da res extensa, ou seja, na esfera da natureza.

Frogneux emprega a expressão "dualismo da pureza" esse dualismo tal qual descrito por Jonas, uma vez que o que pertence à res extensa não se refere à res cogitans e vice-versa, a não ser numa curiosa exceção: o ser humano, no qual as duas rei se unem no interior da "glândula pineal” - formulação cartesiana que Jonas avalia como insatisfatória, por ser artificial.

Além disso, sob a ótica jonasiana, a formulação de Descartes redunda no mais absoluto fracasso, ao postular um homem fragmentado, visto que: o "dualismo cartesiano criou o enigma da maneira pela qual um ato de vontade pode mover um braço, uma vez que uma parte do mundo externo

\footnotetext{
8. A dupla citação indica que nós citamos Frogneux que, por sua vez, cita Jonas.

9. Utilizada por R. Mirashi in Le corps et l'esprit dans la philosophie de Spinoza. Le Plessis-Robinson, Institut Synthélabo, 1998, p. 17. (Apud. VM, p. 121).
} 
somente pode ser movida por outro corpo que lhe transmite seu movimento antecedente" (PhL, p. 61/VM, p. 122).

Mas isso não é tudo, pois, além de toda interação entre res cogitans e res extensa ser recusada na dimensão teórica, o cartesianismo, segundo Jonas, nega a evidência da experiência comum. Por isso, embora admita que a tese cartesiana seja teoricamente consistente; ao se reduzir de um lado à natureza objetivante e de outro ao espírito subjetivante, tal formulação não permite a emergência do organismo vivo. Exatamente esse é o principal problema que Jonas identifica no dualismo cartesiano e que buscará resolver, uma vez que, para ele, que nesse momento pretende conceber uma filosofia da biologia, "o organismo é um fato crucial” ( $P h L$, p. 88/VM, p. 122).

Em suma, Jonas busca enfrentar o dualismo para combater as conseqüências indesejadas, por um lado, de sua versão gnóstica que afirma a vanidade da ação humana no mundo e, por outro lado, da versão cartesiana que, por separar as dimensões: psíquica e física; cria o problema da ação do próprio corpo e impede a real apreensão do organismo. Cabe antecipar, porém, que, nos dois casos, o que está em jogo é a possibilidade da emergência da liberdade (e, ver-se-á adiante, não somente a humana) no mundo ${ }^{10}$.

\section{A solução do dualismo segundo Hans Jonas}

Veremos, agora, como Jonas busca elucidar o problema do dualismo e suas conseqüências indesejáveis. Embora tal questão tenha sido abordada em diferentes textos ao longo de sua produção intelectual, entre os anos 50 e 90 , por sua força sintética e por se tratar de uma versão mais tardia, o texto escolhido para guiar essa exposição foi Evolution und Freheit $(1983-4)^{11}$, que inicia com a seguinte formulação:

\footnotetext{
10. Além desses dois dualismos aqui mencionados, Jonas contesta também o dualismo de tipo kantiano, que retém a liberdade humana à esfera noumenal, tornando-a totalmente ausente na esfera dos fenômenos. Tema que ele aborda em PIS e em outro texto denominado "Le combat pour la possibilité de la foi" em Entre le Néant et l'Éternité, p. 145-174. Jonas contesta ainda a separação humeana entre 0 ser e o dever, "uma vez que certos seres - os viventes - se impõem objetivamente como fim no ser, onde eles aparecem como valores para a consciência capaz de observar esta valorização subjetiva que se esboça bem aquém do sujeito humano" (DH, p. 15-16). Tema que ele expõe em PIS e em PR.

11. Aqui utilizaremos a versão francesa desse texto: JONAS, H. "Evolution et Liberté". In Evolution et Liberté. Traduit de l'allemand et présenté par Sabine Cornille et Philippe Ivernel. Paris: Payot \& Rivages [2000] 2005, p. 25-57.
} 
Nossa tradição filosófica ocidental, o olhar exclusivamente fixo sobre o ser humano, tem o costume de lhe atribuir como uma distinção única uma grande parte do que em realidade tem sua raiz na existência orgânica enquanto tal: ao fazê-lo, ela priva a compreensão do mundo orgânico dos conhecimentos que a percepção que ele tem de si mesmo põe à disposição do homem. De seu lado, a biologia científica, ligada por suas regras às realidades físicas exteriores, somente pode ignorar a dimensão da interioridade inerente à vida: ela deixa assim essa vida, plenamente explicada sob o ângulo material, mais enigmática do que ela estava antes de toda explicação. Esses dois pontos de vista, fixados desde Descartes em sua separação artificial, permanecem complementares um ao outro e se reforçam mutuamente - às custas de seu objeto respectivo, um e outro literalmente reduzidos assim à "porção congruente": a compreensão do humano não sofre menos com essa separação que a compreensão da vida extra-humana. Uma leitura filosófica renovada do texto biológico pode reconquistar a dimensão interior - a parte melhor conhecida por nós - para a compreensão das coisas orgânicas e restituir assim à unidade psicofísica o lugar no conjunto teórico que ela perdeu desde Descartes, em razão do divórcio entre o mental e o material. A partir de então, haverá um ganho tanto para a compreensão do orgânico, quanto para a compreensão do humano. (EL, p. 25-26)

Esse importante parágrafo foi citado na íntegra por fornecer as principais diretrizes para compreender os motivos e objetivos de Jonas. De um lado, os problemas decorrentes da divisão cartesiana: o empobrecimento da compreensão tanto da vida em geral, quanto da vida humana em particular e, de outro, as principais razões para a sua resolução: alcançar uma compreensão integral dessas duas dimensões, eliminando a separação entre o homem e as demais formas de vida.

Curiosamente, o passo seguinte de Jonas não é tentar negar a polaridade, mas, ao invés disso, estendê-la até as mais remotas fronteiras da vida, afirmando que: "As grandes contradições que o ser humano descobre nele mesmo - liberdade e necessidade, autonomia e dependência, eu e mundo, relação e isolamento, criatividade e mortalidade têm já sua prefiguração em germe nas formas mais primitivas da vida, cada uma 
oscilando perigosamente entre ser e não-ser, e portando já em si um horizonte interno de transcendência." ( $E L$, p. 26).

Tal formulação atesta não apenas o caráter eminentemente contínuo e dual da vida em si mesma, mas também o co-pertencimento do ser humano a essa condição. Desde então, o homem não está mais sozinho, isolado numa condição que seria ontologicamente superior, mas ilhada. Toda a contradição que ele experiencia não é, afinal, uma prerrogativa humana, ao contrário, como Jonas ressalta:

Esse tema, comum a toda vida, pode ser seguido em sua evolução através da ordem ascendente desde as faculdades e as funções orgânicas: metabolismo, movimento e desejo, sensação e percepção, imaginação, arte e conceito - um escalonamento contínuo de liberdade e de perigo, que culmina no homem o qual, aí talvez, ganhe uma nova compreensão de sua unicidade, desde que ele deixe de se considerar como metafisicamente separado. ( $E L$, p. 26).

Desse modo, Jonas estabelece uma perspectiva inteiramente diferente para conceber a posição do ser humano na escala do ser vivo. Certamente, influenciado pela teoria da evolução de Darwin ${ }^{12}$, ele pode afirmar a continuidade $^{13}$ existente desde a forma mais elementar de vida até o ser humano, que representa a forma de vida mais complexa - até o momento conhecida. Entretanto, ele admite que,

independentemente dos resultados da pesquisa sobre a
evolução, a presente multiplicidade da vida em sua
simultaneidade, particularmente aquela da vida animal, se
oferece como uma sucessão ascendente de graus, que vai do
"primitivo" ao "desenvolvido", escala sobre a qual se situam
complexificação da forma e diferenciação da função, fineza

12. À qual Jonas atribui grande importância, por sua concepção da vida como processo e por sua reflexão do conceito antigo de "origem" ( $P h V$, p. 53), embora criticando-a em alguns aspectos, sobretudo, na perspectiva do evolucionismo, que contribui para a resolução do dualismo cartesiano tomando partido da matéria em detrimento do espírito, chegando à solução monista materialista, que ele igualmente critica, por excluir a dimensão da subjetividade. (Ver PhV, Ensaio II, p. 51-68).

13. Princípio já postulado por Spinoza e por Leibniz e que Jonas retoma no PhV e no EL, especialmente, pp. 33-34. 
dos sentidos e intensidade das pulsões, controle dos membros e faculdade de agir, reflexão da consciência e apreensão da verdade. ( $E L$, p. 26-27).

Jonas identifica nessa escala ascendente duas vias pelas quais se deu o progresso: 1) a via da percepção; e 2) a via da ação, às quais ele associa respectivamente as dimensões do saber e do poder. Assim, segundo nosso autor, encontramos

de uma parte [a via da percepção] conforme a extensão e a claridade da experiência, segundo os graus ascendentes da presença sensível do mundo que atravessam todo o reino animal para conduzir até a objetivação a mais vasta e a mais livre da totalidade do ser no homem; e de outra parte, paralelamente a isso e culminando igualmente no homem, [a via da ação] conforme a dimensão e a natureza do impacto sobre o mundo, então segundo os graus de liberdade crescente no agir. ( $E L$, p. 27 - itálico nosso).

Tais funções, que se manifestam de modo elementar desde as formas mais primitivas da vida e se tornam cada vez mais complexas até alcançarem um grau mais elevado no ser humano, segundo Jonas, identificam-se no nível orgânico mais primitivo à percepção e mobilidade, cuja inter-relação e interpretação constituem um constante tema de investigação para os estudiosos da vida animal.

Especialmente digno de nota nessa passagem é o conceito de liberdade - mencionado anteriormente no trecho que expôs a evolução como uma ordem ascendente das faculdades - relacionado ao perceber e ao agir já na esfera mais elementar da vida, quando, o próprio Jonas reconhece que, em princípio, não se espera encontrá-la antes do que ele identifica como "domínio do espírito e da vontade" ( $E L$, p. 27). A partir daí, Jonas começa a revelar toda a originalidade de sua formulação, pois, não apenas ele atribui a liberdade às formas mais elementares da vida, como identifica essa primeira manifestação da liberdade àquela mais elementar atividade realizada por todo ser vivo: o metabolismo. Tomando suas próprias palavras: "por nossa parte, nós chegamos mesmo a afirmar que já o metabolismo, camada fundamental de toda existência orgânica, manifesta uma liberdade - ou melhor - que ele próprio é a primeira forma de liberdade" (EL, p. 27-28). 
Num primeiro momento, é bastante difícil acolher essa afirmação sem alguma estranheza, pois como o próprio Jonas indaga: "o que poderia ter menos a ver com a liberdade que o automatismo cego dos processos químicos no interior de nosso corpo?” ( $E L$, p. 28$)$. De fato, segundo a visão convencional, o metabolismo constitui um processo que se passa sem a menor concorrência da vontade, ou seja, é involuntário, razão pela qual não parece guardar qualquer proximidade com o que entendemos geralmente por liberdade. Porém, para nossa surpresa, Jonas pretende "mostrar que, nos movimentos obscuros da substância orgânica à origem do cosmos, surge pela primeira vez, no seio da necessidade incessantemente em extensão do universo físico, o clarão de um princípio da liberdade - estranho aos sóis, aos planetas e aos átomos.” ( $E L$, p. 28 - grifos nossos). Tal formulação de Jonas merece destaque, pois ali ele acaba de afirmar que a forma mais elementar de vida possui algo que, em sua frágil organização, é absolutamente ausente em todo mundo inorgânico, partindo de seus representantes mais ínfimos, como os átomos, chegando até aqueles de dimensões colossais como sóis e planetas. Esse atributo, que integra todo o mundo vivo e o separa do mundo não vivo é precisamente a liberdade, já manifesta no fenômeno do metabolismo.

Jonas reconhece que, para compreender tal conceito em sua nova amplitude, é preciso afastar todas as concepções tradicionais e entender a liberdade sob outra perspectiva, como um modo de ser que diferencia objetivamente o orgânico per se, ou ainda, como algo que, mais que uma maneira de existir, constitui uma prerrogativa de todos os membros da classe 'organismo' e, consequentemente, como algo que somente eles, compartilham. Temos aqui um "conceito ontológico descritivo", pois, segundo ele pensa:

Apesar de toda sua objetividade física, os caracteres descritos por tal conceito no nível primitivo constituem, no entanto, a base ontológica desses fenômenos superiores que merecem mais diretamente o nome de "liberdade"; e mesmo os mais eminentes dentre eles permanecem ligados aos discretos começos na camada orgânica fundamental, que são a condição mesma de sua possibilidade. (EL, p. 28).

A liberdade é revelada, portanto, como um processo crescente que surge já nas mais remotas e elementares formas de vida. Razão pela qual 
Jonas pode afirmar que "tomado nesse sentido fundamental, o conceito de liberdade pode servir de fio de Ariadne para a interpretação do que nós chamamos «vida»" $\left(E L\right.$, p. 29). Ademais, isso estabelece a liberdade ${ }^{14}$ como um conceito fundamental da formulação jonasiana ${ }^{15}$, o que, por sua vez, explica porque na "Introdução" Jonas foi identificado como o filósofo da liberdade.

Contudo, a liberdade, tal qual concebida por Jonas, está longe de ser absoluta, pois, como ele propõe:

(...) o caminho ascendente que parte daí não é implesmente a história de um sucesso. O privilégio da liberdade porta o fardo da aflição e significa: existência em perigo. Porque a condição fundamental desse privilégio reside no fato paradoxal de que, por um ato original de separação, a substância vivente se libertou da integração universal das coisas no todo da natureza para se colocar face ao mundo, introduzindo assim, na indiferente segurança da possessão da existência, a tensão entre "ser e não-ser". (...) Oscilando assim entre ser e não-ser, o organismo somente tem a posse de seu ser de maneira condicional e revogável. Assim, o próprio ser, ao invés de um estado dado, tornou-se uma possibilidade constantemente a realizar, incessantemente a combater seu contrário incessantemente presente, o não-ser, que terminará inevitavelmente por devorá-lo. ( $E L$, p. 29-30).

Jonas descreve, assim, o "fenômeno vida", como uma crescente tensão entre ser e não-ser. $\mathrm{E}$ a liberdade, que emerge e se amplia ao longo de todo o processo, traz consigo o perigo, em idêntica proporção. Trata-se, portanto, de uma "liberdade dialética", que tem o risco permanentemente crescente como sua outra face. Desse modo, também merece destaque o trecho onde podemos ver que

o ser [oscila] assim na (...) polaridade (...) que a vida manifesta constantemente nas antíteses fundadoras entre as quais se

14. "A liberdade é onipresente na obra de Jonas. Já o livro sobre a gnose põe o problema". (DEPRÉ, op. cit. p. 54).

15. Ver PINSART, op. cit. p. 7; e DEPRÉ, op. cit. p. 23. 
desdobra sua existência: ser e não-ser, si e mundo, forma e matéria, liberdade e necessidade. De todas essas polaridades, a do ser e não-ser é a mais fundamental. (...) Porque o não-ser tem para ele a universalidade, a saber, a igualdade de todas as coisas. O desafio que ele propõe ao organismo deve, no fim das contas, terminar na submissão na qual o ser-si desaparece para sempre sob essa forma única. ( $E L$, p. 30$)$.

Cabe notar que o par: liberdade e necessidade, acima referido (p. 06) como uma das "grandes contradições que o ser humano descobre nele mesmo" surge, aqui, pela primeira vez, como expressão do desafio que se coloca a cada organismo para assegurar a própria sobrevivência. E, nesse sentido, a vida é constituída por uma sucessão de batalhas entre o ser e o não-ser, cuja guerra, por fim, será vencida, em cada indivíduo, pelo não-ser.

Adiante, Jonas propõe uma comparação entre e o metabolismo e a atividade mecânica que o motor de qualquer máquina realiza. A máquina seria, segundo ele,

um sistema inerte, idêntico a si-mesmo, face à identidade cambiante da matéria da qual ela se alimenta; e ela continua a existir inteiramente a mesma, uma vez privada de toda alimentação: ela é então a mesma máquina que pára. Ao contrário, quando nós designamos um corpo vivente enquanto "sistema metabolizante", nós devemos incluir aqui que o próprio sistema é inteira e constantemente o produto de sua atividade metabolizante, e que em nenhuma parte desse "produto" não deixa de ser o objeto do metabolismo sendo simultaneamente o agente de sua realização. ( $E L$, p. 36).

Logo, diferentemente dos seres não-vivos, todo ser vivo possui uma tarefa constante que é a sua própria produção e manutenção e que só pode ser assegurada mediante a execução do próprio metabolismo, compreendido como sua permanente troca de matéria com o meio. Por esse motivo, Jonas considera que o organismo poderia ser definido como uma manifestação da matéria metabolizante, ao invés de o metabolismo ser reduzido à mera função do organismo. 
Além disso, Jonas aponta que

no processo do ser se auto-conservando, a relação do organismo à sua substância material é dupla: dependente de sua disponibilidade enquanto que material, ele é independente de sua identidade do momento; sua própria identidade funcional não coincide com a identidade substancial de suas partes que, entretanto, a cada instante o constituem inteiramente. Em uma palavra: a forma orgânica mantém com a matéria uma relação de liberdade na necessidade. ( $E L$, p. 40 - itálico nosso).

E aqui Jonas explicita a outra face do metabolismo - retomando o par conceitual destacado acima - uma vez que ele não é somente expressão da liberdade, que caracteriza todo ser vivo, mas também da necessidade, que impõe que todo organismo o realize constantemente para manter-se vivo. Logo, a liberdade é concebida em relação à esfera (tradicionalmente vista como) diametralmente oposta, da necessidade. Eis uma formulação surpreendente, que contém elementos essenciais para compreender a formulação jonasiana, sobretudo a distinção que ele procura e sobre a qual, adiante, ele afirma: "enquanto que o inanimado (...) pode-se substituir por qualquer outro sem alteração de valor, no organismo, ao contrário, (...) a vida (...) somente pode se encontrar na [dimensão] temporal e na totalidade de suas funções" (EL, p. 40).

A relevância dessa passagem reside em que ela apresenta um importante aspecto para a distinção entre orgânico e inorgânico. A partir dela pode-se inferir que a dimensão espacial está para o inorgânico, assim como a dimensão temporal está para o orgânico. Com efeito, Jonas afirma que:

É o tempo, e não o espaço concomitante, que é o medium da totalidade formal do vivente ${ }^{16}$; e sua temporalidade não é para ele essa exterioridade indiferente que constitui o tempo para os movimentos da matéria e a sucessão de seus estados, mas ela é o modo qualitativo próprio à apresentação da forma vital ela mesma. ( $E L$, p. $40-41)$.

16. Jonas inscreve-se, aqui, embora de maneira absolutamente inovadora, na tradição heideggeriana de Sein und Zeit. 
Jonas demarca, portanto, uma distinção entre o tempo na esfera meramente física, que se constitui como a simples sucessão dos estados da matéria, e o tempo na dimensão propriamente biológica, que se manifesta qualitativamente nas diferentes formas que os indivíduos apresentam ao longo da vida. Além disso, ele chama a nossa atenção para o fato de que, no organismo, a sua "liberdade fundamentaP" se manifesta por uma considerável independência de sua forma em relação à sua matéria. $O$ que se pode compreender considerando as várias transformações sofridas pelos inúmeros organismos desde o surgimento da vida, ao passo que a matéria (embora também atue também nesse processo) tende a se conservar.

Jonas pode, assim, afirmar que "a identidade a si, simples atributo lógico cujo enunciado não vai além de uma tautologia no ser inanimado, [alcança] no ser vivente um caráter de um rico teor ontológico, a realização contínua de sua própria função, face à alteridade da matéria” ( $E L$, p. 41). Ou seja, ele estabelece que a identidade estática e vazia do inorgânico corresponde à identidade lógica do $\mathrm{A}=\mathrm{A}$, enquanto que a identidade orgânica, que é dinâmica e plena de conteúdo, por ser uma identidade ontológica, não é redutível a uma simples fórmula, uma vez que ela

deve ser de outra natureza. (...) É preciso que uma identidade interna do todo, ultrapassando a identidade coletiva do substrato que se encontra cada vez presente e evanescente ao mesmo tempo, supere a série das trocas. Tal identidade interna está implícita na aventura da forma, e ela resulta involuntariamente de seu testemunho morfológico exterior, o único que está acessível à observação. (EL, p. 42).

Surge aqui uma questão: que tipo de observador estaria apto a registrar satisfatoriamente esse processo? Jonas pensa que para se observar a vida é necessário já estar capacitado pela própria vida. Ou seja, antes de tudo, exigese do observador um organismo "dotado de sua experiência própria, afim de que ele seja capaz de extrair a "conseqüência» que de facto ele tira constantemente, (...) a vantagem (...) de ter um corpo, isto é, de ser um corpo". (EL, p. 43). Mas, a quem Jonas está se referindo afinal? Na verdade, a nós mesmos (seres humanos), pois, somos os únicos organismos capazes de “extrair a "conseqüência» ou a vantagem de ter um corpo". Pois, sob a visão 
jonasiana, só nossa "identidade interna (...) permite compreender a continuação do ser como auto-continuação”. ( $E L$, p. 43 - grifos nossos).

$\mathrm{O}$ que ele acaba de propor não é, o que pareceria mais evidente, a exclusividade da compreensão humana sobre o processo vital - embora, até onde sabemos, a capacidade de tal compreensão seja mesmo uma prerrogativa eminentemente humana -, mas algo ainda mais instigante: a introdução do conceito de "si", pressuposto na noção de identidade interna. O que ele define como: "Uma identidade que se faz a cada instante (...) [e que] se encontra numa tensão essencial com a totalidade das coisas (...). Numa perigosa polarização onde (...) tudo o que não é ela mesma assume o caráter de uma incondicional alteridade" (EL, p. 43-44).

Vimos surgir, assim, outra polaridade irredutível, aquela entre ipseidade $\mathrm{x}$ alteridade que, mais uma vez, já se manifesta desde as formas mais elementares da vida. Posto que o

desafio da ipseidade designa tudo o que está além dos limites do organismo como alguma coisa de estrangeira e, de algum modo, oposta: como o "mundo" no qual, pelo qual e contra o qual a vida deve se manter. Sem essa oposição universal da alteridade, não poderia haver a ipseidade. E, nessa polaridade do si e do mundo, do dentro e do fora, que completa aquela da matéria e da forma, é potencialmente posta a situação fundamental da liberdade, com toda a audácia e a miséria que ela comporta. (EL, p. 44).

\section{Consequências dessa formulação}

A partir dessa exposição, podemos extrair cinco importantes conseqüências:

1. Tal concepção de Jonas é importante, entre outros motivos, porque ao invés de, como se poderia criticar, reduzir a dignidade do ser humano, ela amplia essa dignidade a todo ser vivo, ao fazer da liberdade não só um atributo, mas uma condição inalienável de todas as formas de vida, desde as mais elementares. Nesse sentido, poderíamos aplicar a tal concepção de Jonas o mesmo comentário que ele fez em relação à teoria da evolução de Darwin, quando ele afirma que: 
$\mathrm{Na}$ ruidosa indignação que se ergueu contra o atentado à dignidade do homem pela doutrina de sua origem animal, não se viu que em virtude do mesmo princípio era a totalidade do mundo vivo que recebia alguma parcela da dignidade do homem. Se o homem é aparentado aos animais, os animais são, por sua vez, aparentados ao homem, e então, por graus, portadores dessa interioridade [e da liberdade], da qual o homem, o mais avançado de seu reino, é intimamente consciente. (EL, p. 33-34).

Assim, ele transpôs o abismo que separava o homem e o mundo, restituindo ao homem sua condição de integrante do mundo, em estreita relação com todos os demais seres vivos.

2. Mas, além dessa conseqüência no plano ontológico ${ }^{17}$, poderíamos incluir, seguindo Frogneux, outra importante conseqüência dessa formulação de Jonas, também para o plano ético, uma vez que, partindo dessa discussão ele poderá: "estabelecer no nível ético uma dialética equivalente àquela que ele tinha evidenciado no nível orgânico. À dialética da liberdade e da necessidade metabólica corresponderia a dialética do valor e da obrigação ética se impondo à liberdade humana.” (VM, p. 274).

3. Explicitando um pouco melhor essa dimensão, Frogneux nos conduz à próxima conseqüência, uma vez que, segundo ela, a partir dessa análise, do "plano imanente da biologia filosófica e da ética, onde ele afronta o dualismo em [diferentes] níveis: em primeiro lugar, o dualismo cosmológico que opõe o homem à natureza, em seguida, o dualismo antropológico que opõe a causalidade física à intenção subjetiva, [Jonas poderá], enfim, [afrontar] o dualismo moral que opõe o ser ao dever-ser" (VM, p. 274).

4. É ainda Frogneux que nos mostra que tudo isso só foi possível, graças ao "princípio da continuidade, [segundo o qual] a liberdade se manifesta cada vez mais claramente no mundo do vivente, onde ela faz aumentar, ao mesmo tempo em que ela [própria], a precariedade e o risco" (VM, p. 275).

17. Frogneux considera que há aqui também uma dimensão ética, a partir do que se poderia pensar num plano "onto-ético". 
5. Por fim, no plano conceitual cabe mencionar a importante transformação que Jonas realiza num conceito fundamental na tradição filosófica: o conceito de liberdade que foi ampliado a todo ser vivo e que, embora desempenhe um papel absolutamente central em sua formulação, não corre o risco de se tornar uma liberdade absoluta. Pois ele próprio reconhece, segundo Frogneux, que

a liberdade recepta uma potência de tal modo invencível que ela somente pode reconhecer os limites que ela mesma se fixou. [E que] (...) essa liberdade, por essência reflexiva, pode cair no abismo da auto-contemplação se ela se abstrai de toda relação a uma exterioridade. (...) [Para que isso não aconteça, Jonas estabelece que] ela somente pode se compreender autenticamente numa relação estreita com a necessidade e em seu caráter relativo à exterioridade sobre a qual ela faz fundo. (VM, p. 275, grifos nossos)

Desse modo, Jonas concebe a liberdade como prerrogativa de todo ser vivo e em relação dialética com a necessidade, como constituição do organismo que pode e deve $\mathrm{e}^{18}$, permanentemente, realizar o metabolismo.

Cabe ainda ressaltar que, todas essas conseqüências são bastante significativas para se pensar a fundamentação de uma reflexão eco-ética, uma vez que estabelecem uma relação de continuidade entre o homem e todos os demais seres vivos.

\section{Conclusão}

Vimos o percurso realizado por Jonas para resolver o problema do dualismo e cabe chamar a atenção para o fato de que, no decorrer de sua exposição, as polaridades não desaparecem, ao contrário, elas vão se multiplicando: ser/não-ser, vivo/não vivo, orgânico/inorgânico, interior/exterior, si/mundo, ipseidade/alteridade, liberdade/necessidade, etc. Cabe, portanto, perguntar: Jonas teria conseguido, afinal, solucionar o problema do dualismo ou, ao contrário, ele o teria exacerbado?

18. Essa relação entre liberdade e necessidade na dimensão ética transforma-se na relação entre liberdade e responsabilidade, uma vez que "para Jonas a responsabilidade é o fardo da liberdade humana." (PINSART, op. cit. p. 205). 
Para responder a essa questão - que não é retórica, mas absolutamente legítima dentro da reflexão proposta -, é preciso ter em mente o que foi apresentado no tópico 1 , como razão principal de sua crítica tanto ao dualismo gnóstico quanto ao dualismo cartesiano. Cabe lembrar: a crítica de Jonas ao dualismo voltou-se, sobretudo, às conseqüências indesejadas, do gnóstico: a vanidade da ação humana no mundo e do cartesiano: a separação psíquico-física resultando no problema de explicar a ação do próprio corpo e na impossibilidade de se apreender o organismo. Lembrando que, nos dois casos, o que ele pretendia era mostrar a possibilidade de emergência da liberdade (e não apenas a humana) no mundo. Com efeito, vimos, ao longo de toda essa trajetória, ele se empenhar em demonstrar a relação entre a emergência do organismo e a possibilidade da liberdade.

Todavia, ele não pretendeu alcançar tais objetivos de maneira puramente teórica e distante da realidade, ao contrário, partindo da realidade, ela mesma ${ }^{19}$. Nesse sentido, a formulação de Jonas é única, já que, ao refletir sobre o fenômeno da vida, ele encontra não um dualismo radical que separa os seus elementos constitutivos, mas, antes, revela inúmeras dualidades que expõem seus pólos a uma constante relação dialética ${ }^{20}$. Assim é a vida, esse permanente "embate" entre os opostos que se contrapõem, mas que, ao invés de se anularem, se completam contínua e simultaneamente.

A riqueza da exposição jonasiana é precisamente explicitar esse processo sem reduzir a contradição a um de seus pólos, mas, demonstrar que aí, justamente, reside a complexidade, a diversidade e a insuperável fecundidade da vida. Assim, nosso título propõe a 'resolução' e não a 'superação' do dualismo. Resolução ${ }^{21}$ porque é a maneira pela qual Jonas "resolve" no sentido de desvendar - como uma incógnita matemática - esse

19. Uma vez que Jonas preservou o princípio essencial das lições que recebeu de Heidegger em Marbourg, quando da elaboração de sua analítica do Dasein como ontologia fundamental, segundo 0 qual "a ontologia somente é possível como fenomenologia". (TAMINIAUX, J. "Sur une ethique pour l'âge technologique”. In Le Messager Européen, 5, Paris: Gallimard, 1991, p. 187-202, aqui p. 187-188). Tal coerência explica suas críticas à formulação cartesiana que, embora teoricamente consistente, recusam a realidade e ao idealismo de Leibniz e pode ser constatada, sobretudo, no Phénoméne de la Vie.

20. Neste contexto, podemos compreender as palavras de Frogneux ao descrever o pensamento jonasiano: "Pos-dualista, sua filosofia busca uma via média, aquela de um monismo polarizado entre um monismo monolítico, primitivo e redutor, e um dualismo radical que quebra a unidade do real e aniquila 0 mundo da ação." (DH, p. 16)

21. Cabe também destacar entre os sentidos do verbo resolver, três que seriam especialmente adequados a essa elaboração jonasiana, a saber: "Reduzir, mudar, transformar em". 
problema, sem aniquilá-lo, neutralizá-lo ou reduzi-lo a um dos extremos, mas simplesmente elucidá-lo. Por esse motivo se disse (p. 3) que para Jonas não existe uma oposição entre dualismo e monismo, assim como existe entre monoteísmo e diteísmo. Porque, segundo ele, na verdade o monismo radical é tão criticável quanto o dualismo radical, porque ambos inviabilizam a relação entre os elementos opostos. Por esse motivo também se disse que Jonas pretendia reter algo do dualismo e não apenas descartá-lo inteiramente. Pois, como vimos, sua crítica não se dirige ao dualismo em si mesmo, mas às conseqüências niilistas que dele foram extraídas.

Por fim, poderíamos concluir dizendo que o mais importante dessa reflexão de Jonas foi ter mostrado a conexão entre o homem e o mundo, o corpo e o "espírito" 22 e ter pensado a liberdade numa relação dialética com a necessidade. Demonstrando que não há entre esses elementos uma contradição excludente, mas como efetivamente se dá na realidade, uma relação dialética: uma legítima e necessária complementaridade entre os opostos. Nesse sentido, o dualismo radical, transforma-se, no pensamento jonasiano, numa fecunda dualidade consoante com a realidade e com a própria vida.

22. Sobre o que as palavras de Ricœur impõem-se, ao afirmar que "com o metabolismo, a dimensão da interioridade se revela como pertencente à vida e o fenômeno de auto-organização torna caduca a nociva oposição entre corpo e alma." (RICOEUR, P. op. cit. p. 208) 


\section{Referências}

JONAS, H. "Evolution et Liberté". In Evolution et Liberté. Traduit de l'allemand et présenté par Sabine Cornille et Philippe Ivernel. Paris: Payot \& Rivages [2000] 2005, p. $25-57$.

The phenomenon of life. Toward a Philosophical Biology. New York: Harper \& Row, 1966.

- Le phénoméne de la Vie. Vers une biologie philosophique. Traduit de l'allemand par Danielle Lories. Bruxelles: De Boeck \& Larcier, 2001.

Organismus und Freihet. Ansätse zu einer philosophischen Biologie. Göttingen: Vandenhœek \& Ruprecht, 1973.

. Philosophical Essays: From Ancient Creed to Technological Man. Englewood Cliffs, New Jersey: Prentice-Hall, 1974.

- Das Prinzip Verantwortung. Versuch einer Ethik für die technologische Zivilisation. Frankfurt am Main: Insel, [1979] 1984.

Le Principe Responsabilté. Une éthique pour la civilisation technologique. Traduit de l'allemand par J. Greisch, Paris: Flammarion, [1990] 1995.

Puissance ou impuissance de la subjectivité? Le probléme psichophysique aux avant-postes du Principe Responsabilité. Traduit de l'allemand par Christian Arnsperger. Revue et présenté par Nathalie Frogneux. Paris: Cerf, [1981] 2000.

. Le Concept de Dieu aprés Auschwitz - Une voix juive. Traduit de l'allemand par Philippe Ivernel. Paris: Payot \& Rivages [1984] 1994.

"Le combat pour la possibilté de la foi" in Entre le Néant et l'Éternité. Textes rassamblés par Sylvie Courtine-Denamy.Paris: Édtions Belin, 1996, p. 145-174.

DEPRÉ, O. Hans Jonas (1903 - 1993). Paris: Ellipses, 2003.

FROGNEUX, N. Hans Jonas ou la vie dans le monde. Bruxelles: De Boeck \& Larcier, 2001.

"La puissance de la subjectivité comme dignité de l'homme”. Présentation à Puissance ou impuissance de la subjectivité? Le problème psichophysique aux avantpostes du Principe Responsabilité. Traduit de l'allemand par Christian Arnsperger. Revue et présenté par Nathalie Frogneux. Paris: Cerf, [1981] 2000, p. 9-24.

GREISCH, J. \& GILLEN, E. "De la gnose au Principe Responsabilité". Un entretien avec Hans Jonas, in Esprit, 54 (mai 1991), p. 5-21.

LORIES, D. \& DEPRÉ, O. Vie et liberté. Phénoménologie, nature et éthique chez Hans Jonas. Paris: Vrin, 2002. 
MARÉCHAL, J. (s.j.) Précis d'Histoire de la Philosophie Moderne. Tome Premier: De la Renaissance à Kant. Deuxième édition revue et augmentée avec supplément bibliographique de 1933 a 1949. Bruxelles: L’Édition Universelle/Paris: Desclée de Brouwer, 1951.

NEVES, F. "The Phenomen of Life - 1966", in Kriterion, 68, Belo Horizonte: UFMG, 1975, p. 172-178.

PINSART, M-G. Jonas et la Liberté. Dimensions théologiques, ontologiques, éthiques et politiques. Paris: Vrin, 2003.

RICEUR, P. "La responsabilité et la fragilité de la vie". In Le Messager Européen, 5, Paris: Gallimard, 1991, p. 203-218.

TAMINIAUX, J. "Sur une Éthique pour l'âge technologique". In Le Messager Europée, 5 Paris: Gallimard, 1991, p. 187-202.

Email: filoslgodoy@ig.com.br

Recebido em: Setembro/2010 Aprovado em: Outubro/2010 